\title{
Research on hazard installations identification method of power equipment in ship
}

\author{
Yue Wang, Guobing Chen*, Jun Chen, and Guoqing Zeng \\ College of Power Engineering, Naval University of Engineering, 430000 Wuhan, China
}

\begin{abstract}
Hazard installation identification was the key and difficult point for ship power equipment safety management. According to the characteristics of ship power equipments, this article analyzed the characteristic of hazard installations, given the range and classification of hazard installation identification. Combining hazard installation checklist and routing inspection, the method and process of hazards installation identification was proposed for ship power equipment, which laid a foundation for its risk assessment and control.
\end{abstract}

With the increasing frequency of marine activities in our country, the safety of ships, tankers, cargo ships and other large ships has attracted more attention. Safety management is one of the core tasks of large ships. Due to the numerous and centralized equipment of large ships, the huge and complex system, and the far more complex working environment than land, the safety management risk of large ships is greater. Once an accident occurs, it will have a serious impact. Power equipment is the core equipment of ships. There are many special equipment, such as boilers, high temperature and high pressure pipelines, etc., which require high safety management. Therefore, the safety management of power equipment will directly affect the safety and vitality of ships.

Safety management takes "danger" as the core, conducts risk assessment on it, and proposes corresponding emergency management and control measures. However, due to the complexity of ship power equipment and the harsh working environment, there are many unpredictable potential risks and random factors, and it is very difficult to identify hazards. The current research on the identification of hazards is mostly concentrated in industries such as land power generation, coal, chemical industry, and nuclear power [1-2], and less involved in the shipbuilding industry; at the same time, the research content mainly focuses on the production process and chemical storage management [3], etc. , Less attention is paid to the safety management of ship power equipment. Therefore, to carry out research on the identification method of hazard sources of marine power equipment is of great significance to the safety management of marine equipment, and has become an important task currently facing.

${ }^{*}$ Corresponding author: chenguo@,163.com 


\section{Characteristics of hazard sources of marine power equipment}

\subsection{Definition and identification of hazards}

There are many definitions of hazard, and Willie Hammer believes that hazard is a potential unsafe factor that may cause casualties or property damage accidents [4]. The U.S. Occupational Safety and Health Management Center believes that: "The hazard is a potential factor that may cause injury, damage or harm" [5]. These two definitions mainly emphasize that hazards are potential factors that can cause accidents. my country's GB/T 28001-2011 defines the hazard as: the source, state or behavior, or its combination that may cause personal injury and/or health damage, and it is clear that the hazard is the source, state and behavior that may cause an accident [6 ]. Hazard identification is the process of identifying the existence of hazards and determining their characteristics. The main methods are: safety checklist, initial risk judgment, failure type and influence analysis, operation hazard analysis and fishbone diagram analysis, etc. It has its characteristics, so the applicable scenarios and scopes are also different [7].

\subsection{Characteristics of hazard sources of ship power equipment}

The ship power system is a large-scale and complex mechanical system. Its main characteristics are complex structure, concentrated special equipment, and difficult to identify potential hazards, which brings difficulties to the identification of its hazard sources.

(1) The system is huge and complex with numerous sources of danger

Take the ship steam power system as an example. It consists of the main steam turbine gear unit and shafting, booster boiler, turbocharger unit, steam turbine feedwater unit, deaerator, steam turbine circulating water pump, steam turbine oil pump and electric oil pump, steam Fuel pumps, electric fuel pumps, monitoring systems, etc., involving a large number of special equipment and piping systems [8], the difficulty of safety management and hazard identification is far greater than that of land equipment.

(2) Accidents happen frequently, with serious consequences

Due to the harsh marine environment (high salt spray), harsh working requirements (high temperature and humidity, vibration, noise, etc.), and small space, the failure rate of ship power equipment has greatly increased, and the factors that cause accidents have increased, and they affect each other. Due to the lack of timely shore-based protection, the consequences of equipment accidents are also more serious.

(3) Hazards are widely distributed and difficult to identify

On ships, there are many types of equipment in power equipment, and the hazards of each equipment are different, and the performance characteristics of each type of hazard are also different. At the same time, high-temperature and high-pressure steam, high-pressure and high-purity oxygen, nitrogen, high-pressure hydraulic oil, etc., the preparation, storage compartments and transfer pipelines of such dangerous sources are distributed throughout the ship. This also brings a lot of trouble to the identification of hazard sources of power equipment [9].

(4) Human factors

People have many weaknesses in safety, which are plastic and difficult to control. Misoperation, psychological influence, unreasonable behavior, etc. will cause damage to the system and affect personnel safety [10]. Due to the harsh working environment of power equipment, coupled with the influence of factors such as sea conditions and long hours of duty, the consequences of accidents caused by human problems are very serious and require sufficient attention. There have been many profound lessons in this regard.

(5) High safety management requirements 
Due to the particularity of the tasks of ships, oil tankers, and freighters, extremely high requirements are put forward for the safety management of power equipment, such as high mobility, economy, reliability, safety, and ocean navigation. During long-term ocean voyages, due to the high intensity of equipment use, the inability to achieve land support, and the sharp increase in personnel operating pressure, accidents occur more frequently, which brings challenges to its safety management, and proposes more dangerous source identification. High demands.

\section{Identification method of hazard sources for ship power equipment}

\subsection{Identification scope of hazard sources of power equipment}

In ship power equipment, the identification of hazard sources should be comprehensive, systematic, and without omissions, and the two working conditions of navigation and berthing should be fully recognized, and normal conditions should be considered in handling. In particular, it is necessary to focus on unconventional and emergency conditions. The scope of identification should be Highlights include the following:

(1) Power equipment and its working medium: including the high temperature, hazardous materials, noise, radiation, flammable and explosive dangerous goods involved, the layout of power equipment, etc.[11];

(2) Working environment: including external environment, such as ocean, climate, wind and waves, etc., but also internal environment, such as cabin environment, layout, equipment operating conditions, etc.;

(3) Human behavior factors: including the physical and mental state of personnel, the level of personnel operation, psychological factors, etc.;

(4) Special devices and equipment: such as boilers, lubricating oil, fuel oil storage and transportation equipment, etc.;

(5) Work high-risk parts: work involves dust, radiation, noise, vibration, high and low temperature and other working parts of power equipment.

At the same time, the following aspects should be specially considered:

(1) Equipment and environment where accidents have occurred;

(2) When performing different tasks, it is necessary to evaluate the hazard sources differently, such as sailing during the day and navigating at night, sailing in extreme weather, etc.; we have to distinguish whether the ship is sailing or berthing. In the berthing state, there are many dangerous sources. It belongs to the latent state, the system hazard source basically has no external factors that can inspire the hazard source, and more importantly, it is the control of human behavior; and the hazard source is always in a state that may be stimulated by external factors at any time during the navigation. ;

(3) Equipment and cabins that need key damage control. Damage control is an important measure for ship safety management. The focus is on water ingress and fire. Therefore, for power equipment, it is necessary to carry out hazard identification around its damage control requirements.

\subsection{Classification of hazard sources of ship power equipment}

In order to facilitate the identification and analysis of hazard sources, the hazard sources of ship power equipment should be classified. According to the characteristics of ship power equipment and the working environment, it can be divided into the following four categories.

(1) Physical hazards 
(1)Equipment failure, insufficient bearing capacity of components and structures due to design and use; (2) Protection defects and improper support, such as failure of hightemperature insulation materials; (3) Electrical hazards, lightning, static electricity and electromagnetic radiation, etc.; (4)Vibration hazards, such as When sailing in high winds and waves, equipment vibration, hull vibration, etc.; (5)High temperature substances, such as high temperature gas (gas, flue gas, steam), liquid, solid (exhaust pipe, etc.); (6) Low temperature substances, such as low temperature oxygen, etc.; (7)Working environment, In the engine room of ships, the characteristics of poor working environment, poor ventilation, excessive temperature, high temperature and high humidity are particularly obvious. In order to improve the vitality, the main compartment of the ship is separated by a watertight next wall, and the entry and exit of the compartment must be straight up and down, which is prone to accidents such as falling; (8) other physical hazards.

(2) Chemical hazards

(1)Inflammable and explosive substances; (2)Toxic substances; (3)Corrosive substances; (4) Other chemical hazards.

(3) Psychological and physical hazards

(1) Excessive load, due to long-term sailing, causing excessive physical, hearing, and visual load; (2) Dangerous operations, such as diving, plugging, fire fighting, etc.; (3) Psychological abnormalities, such as emotional instability, excessive tension, and other psychological abnormalities, etc. (4) Identification function defects, such as delayed perception, identification errors, other identification function defects, etc. [12]; (5) Other psychological and physical hazards.

(4) Behavioral hazards

(1)Command errors, such as improper command, illegal command, other command errors, etc.; (2) Operation errors, such as misoperation when facing an emergency, knowingly violated operations, simple and rough operations, other operational errors, etc.; (3) Monitoring errors; (4) Others Behavioral hazards.

\subsection{Hazard identification process}

Traditional hazard identification methods include safety checklists, fault trees, etc. [13]. The safety checklist can check the hazard sources and equipment status very well, but only the identified hazard sources can be checked. Analysis methods such as fault tree are difficult to make quantitative analysis when the data is small. For ship equipment, on the one hand, the key to identification of hazards is to find potential hazards, and the identified hazards have corresponding management measures; on the other hand, the equipment can collect less data and it is difficult to analyze with quantitative methods. . Therefore, it is necessary to carry out the identification of hazards in light of the actual working conditions of the ship's power equipment.

Large ships generally have safety departments and various safety inspection systems. Such as the inspection system, the crew on duty within the specified time from the bow to the stern of the ship to patrol the important equipment and cabins in turn. The inspection system can check the status of the equipment in time and find the source of danger. However, the potential source of hazard cannot be found in the inspection, and the possible consequences are underestimated, which may cause serious accidents to the crew and the ship.

In the actual process, the "Work Register" is often used on ships. Its main function is to register equipment status, failures and maintenance, but the content of the registration is relatively broad and cannot be well used for hazard identification, risk assessment, etc. . In 
order to overcome the deficiencies of safety checklists, work registers, etc., and find potential sources of hazards, this article has developed a hazard checklist to allow crew members to identify the hazards of related equipment in an effective classification.

Table 1. Checklist of hazard installations.

\begin{tabular}{|c|c|c|c|c|c|}
\hline $\begin{array}{c}\text { Inspection } \\
\text { department }\end{array}$ & \multicolumn{2}{|c|}{$\begin{array}{c}\text { check the } \\
\text { time }\end{array}$} & \multicolumn{2}{|c|}{$/ / /$} \\
\hline System & \multicolumn{2}{|l|}{$/$ Inspectors } & \multicolumn{2}{|c|}{} \\
\hline Numbering & Item & $\begin{array}{c}\text { Check } \\
\text { content }\end{array}$ & Hazard & $\begin{array}{c}\text { Features and } \\
\text { consequences }\end{array}$ & Remarks \\
\hline & & & & & \\
\hline & & & & & \\
\hline
\end{tabular}

Before identifying the hazard, the crew should be organized to learn about the hazard, so that the crew can identify the hazard scientifically and quickly. At the same time, it is necessary to further grasp the structure and function of the equipment, and then combine with the daily inspection work to organize the crew to effectively identify the hazard sources of the equipment. The process is as follows:

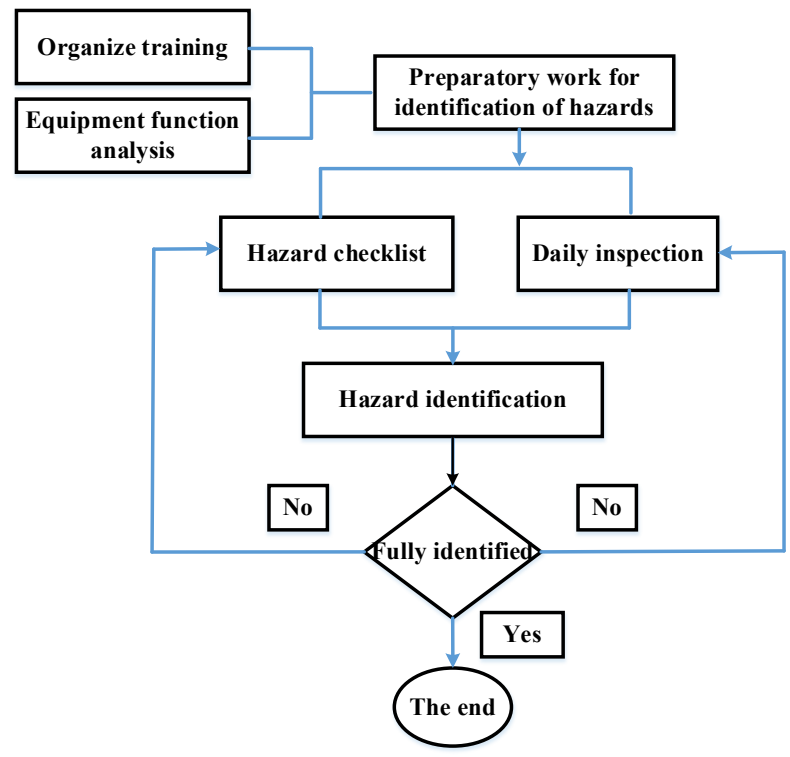

Fig. 1. Hazard identification flow chart of power equipment.

\subsection{Improved LEC method}

\subsubsection{Introduction to LEC method}

The LEC method is a semi-quantitative evaluation method for the hazard of operators when working in an environment with uncertainty or potential danger. It uses the product of the index values of three factors related to the system risk rate to evaluate the risk of system equipment and personnel injury. The three factors are the probability of an accident (L), and the human body is exposed to this dangerous environment. The frequency (E) and the consequences of losses in the event of an accident (C) [14]. Then, according to the actual 
situation, considering the scores of the three factors in different situations, the evaluated objects are "scored" according to the situation, and then the risk scores are calculated, and the risk scores are classified according to the actual experience. Table to find out the evaluation method of its hazard, which is a simple and easy method to evaluate the hazard of working conditions [15].

\subsubsection{Improved LEC method}

However, in the risk assessment of hazards in the power system, the conventional LEC method has certain problems, such as the rough classification of hazards, and it is impossible to carry out effective and detailed risk assessment on the hazards of the power system. Based on the relevant literature and combined with the actual situation of the power system, the existing LEC method is improved.

The specific expression of this method is that for a potentially dangerous business condition, there are three main factors affecting the risk in the power system:

L_ - The possibility of accidents or dangerous events;

$\mathrm{E}$ - The frequency of exposure to this dangerous environment;

$\mathrm{C}$ - The possible consequences once an accident occurs.

This definition can be formalized as:

$$
D=L E C
$$

where $\mathrm{D}$ is the risk of operating conditions.

The scores of the above three potentially dangerous operating conditions are determined (see Table 2, Table 3, and Table 4 for the values of L, E, and C, respectively), and calculated according to the formula, then the score of risk D can be calculated. value. Based on this, when determining the degree of danger, the actual conditions of the power system are combined with the classification or assessment of the danger level according to the scores shown in Table 5.

Table 2. Accident possibility (L).

\begin{tabular}{|c|c|}
\hline Point value & Possibility of accident (L) \\
\hline 10 & It is entirely possible to anticipate or need to be dealt with at any time. \\
\hline 6 & It is quite likely to happen and needs to be overhauled and maintained weekly. \\
\hline 3 & Possible, but infrequent, requires monthly maintenance. \\
\hline 1 & $\begin{array}{c}\text { The possibility is small, completely accidental, and maintenance is required during } \\
\text { annual inspections. }\end{array}$ \\
\hline 0.5 & Very impossible, but it can be imagined. \\
\hline 0.2 & Very unlikely \\
\hline 0.1 & Actually impossible \\
\hline
\end{tabular}

As shown in Table 2, the possibility of accidents on a ship is based on the fact that the power system does not actually exist in the latter three states. Once the hazard source of the latter three states described during navigation breaks out, it will cause irreparable damage, Whether for the crew or the ship itself. Therefore, according to the risk of the accident, the possibility of the accident is considered, and the scores of the latter three states are all calculated according to the score 1 of the fourth state "the possibility is small, completely accidental, and maintenance during annual maintenance". 
Table 3. Frequency of exposure to hazardous environment (E).

\begin{tabular}{|c|c|}
\hline Point value & Frequency of exposure to hazardous environment (E) \\
\hline 10 & Continuous exposed. \\
\hline 6 & Daily working exposed. \\
\hline 3 & Exposed once a week. \\
\hline 2 & Exposed once a month. \\
\hline 1 & Exposed several times each year. \\
\hline 0.5 & Very rare exposed. \\
\hline
\end{tabular}

As shown in Table 3, when the crew is working in the power engine room, depending on the number of oars used during the sailing period of the ship, the time of exposure of the crew is different. In this risk assessment process, the four oars will work at the same time or Do not work at the same time in the parked state for risk assessment. However, no matter which state of the ship, there are only two exposure states for the crew: continuous exposure and exposure during daily working hours.

Table 4. Consequences of accidents (C).

\begin{tabular}{|c|c|}
\hline Point value & The consequences of an accident $(\mathrm{C})$ \\
\hline 100 & Catastrophe, multiple casualties, irreparable damage to the entire ship. \\
\hline 40 & Disaster, several casualties, irreparable damage to equipment. \\
\hline 15 & Very serious, one person died, equipment damage. \\
\hline 7 & $\begin{array}{c}\text { The personnel are severely injured, it affects the normal operation of the } \\
\text { equipment. }\end{array}$ \\
\hline 3 & Major accident and disability. \\
\hline 1 & Personnel injured and need ambulance. \\
\hline
\end{tabular}

As shown in Table 4, after the hazard source of the ship is triggered, not only the damage to the person, but also the damage to the hull of the ship must be considered after the accident.

Table 5. Hazard classification (D).

\begin{tabular}{|c|c|c|}
\hline Point value & The level of danger & Risk level \\
\hline$>400$ & $\begin{array}{c}\text { Extremely dangerous, the ship must stop sailing and enter the } \\
\text { factory }\end{array}$ & 1 \\
\hline $320 \sim 400$ & Major danger, the ship must be suspended for maintenance & 2 \\
\hline $160 \sim 320$ & Highly dangerous, check and repair immediately & 3 \\
\hline $70 \sim 160$ & Significantly dangerous and need to be protected at all times & 4 \\
\hline $20 \sim 70$ & General danger, need to pay attention when working & 5 \\
\hline$<20$ & Slightly dangerous, acceptable & 6 \\
\hline
\end{tabular}

It can be known from experience that environments with a hazard score of less than 20 are considered low-risk and can generally be accepted by the crew. Similar hazards generally occur. For example, due to the small space, they may meet at any time, requiring the crew to protect themselves at all times. When the hazard score is between 20 and 70, the crew should pay attention to and protect them during operation. When the score is 70 to 160 , it is a significantly dangerous operating condition, and measures need to be taken to rectify it. At the same time, protective equipment is generally placed in an obvious location. Similarly, combined with experience, the situation with a score of 160 320 is highly dangerous, and relevant measures must be taken immediately to repair. When the risk score is between 320 and 400, it means that the operating conditions are severely dangerous and should be suspended and overhauled immediately until the dangerous situation is improved or disappeared. When the hazard score is above 400, the ship must be repaired in the factory, otherwise, if an accident occurs, the ship may be damaged. 
The risk assessment of ship power equipment should be linked to its actual operating conditions, refer to past experience, not only to evaluate the consequences of possible accidents, but also to analyze the possibility of occurrence according to the actual situation, so as to develop a hazard identification and evaluation table.

For the hazard sources of ship power equipment, the direct judgment method can be used, or methods such as the risk assessment of operating conditions can be used. There are several situations that can be directly judged as higher-level risks:

(1)Comply with occupational health and safety laws, regulations and other requirements;

(2)After an accident has occurred, no preventive and control measures have been taken so far;

(3)Directly to errors that may cause danger, and without proper control measures.

Determination of major hazards. When the following situations occur, it can be determined to be a major source of danger:

(1)Violation of relevant laws and regulations and other requirements;

(2)Risk assessment is determined as the hazard source of level 1, level 2, and level 3.

Corresponding to the risk assessment results and the above requirements, Table 6 is available.

Table 6. Improved hazard classification table.

\begin{tabular}{|c|c|c|}
\hline \multicolumn{2}{|r|}{ Risk level } & \multirow{2}{*}{ Control measures } \\
\hline Code & Name & \\
\hline 6 & Negligible risk & $\begin{array}{l}\text { No control measures or written records are required, and daily attention } \\
\text { of the crew is required. }\end{array}$ \\
\hline 5 & Tolerable risk & $\begin{array}{l}\text { It is reflected in the monitoring system at any time, and there are } \\
\text { corresponding control measures and skilled control methods. }\end{array}$ \\
\hline 4 & Mild risk & $\begin{array}{l}\text { Withdrawal in the monitoring system at any time, the cost of reducing } \\
\text { the risk is low, and the outbreak can be controlled immediately on the } \\
\text { ship, and the protective equipment is generally placed in an obvious } \\
\text { location. }\end{array}$ \\
\hline 3 & Moderate risk & $\begin{array}{l}\text { Efforts should be made to take measures to reduce risks, and preventive } \\
\text { costs should be carefully measured and limited at all times. Measures } \\
\text { should be implemented within an effective time to reduce risks. If the } \\
\text { corresponding conditions are not available at that time, long-term } \\
\text { measures and current simple control measures can be considered. Once } \\
\text { an outbreak occurs on a ship, it can effectively reduce the risk and } \\
\text { ensure the ship's normal navigation. }\end{array}$ \\
\hline 2 & $\begin{array}{l}\text { Significant } \\
\text { risk }\end{array}$ & $\begin{array}{c}\text { Only when the risk is reduced can you start working. At this time, a } \\
\text { large amount of resources must be allocated in order to reduce the risk. } \\
\text { When the risk involves the work in progress, emergency control } \\
\text { measures should be taken, and corresponding goals and management } \\
\text { plans should be formulated. After an outbreak, it can be controlled } \\
\text { within a certain range to ensure that the ship sails, but it needs to be } \\
\text { repaired after returning to the ship. }\end{array}$ \\
\hline 1 & $\begin{array}{c}\text { There is a } \\
\text { clear risk of } \\
\text { destructiveness }\end{array}$ & $\begin{array}{l}\text { Only when the risk treatment is completed, can the work be started or } \\
\text { continued. If the investment of unlimited resources cannot reduce the } \\
\text { risk, work must be stopped and non-maintenance personnel are } \\
\text { prohibited from entering this area. After the outbreak, the tugboat } \\
\text { needs to be towed back to the factory for repair, and the ship is even } \\
\text { completely damaged. }\end{array}$ \\
\hline
\end{tabular}

After the improved LEC method is used to conduct risk assessment on hazards of ship power equipment, the crew can clearly recognize the serious consequences caused by the hazards caused by external factors, and strictly manage them by level. 


\subsection{Organization and implementation of hazard identification for power equipment}

(1) Matters needing attention in the identification process

(1) Some crew members do not understand the source of danger, and the questions actually obtained in the inquiry are somewhat deviated from the real source of danger;

(2) The space of the power engine room is narrow, which makes it difficult to implement part of the work during on-site observation;

(3) It is sometimes difficult to obtain useful information in daily tasks in the engine room.

In order for the crew to effectively identify the hazard source and intuitively recognize the seriousness of the hazard source, the crew should first be trained on the hazard source knowledge and use the "Hazard Source Checklist" to identify the hazard source of each equipment.

(2) Conditions of use of the hazard checklist

When using the hazard checklist, you must first have a detailed knowledge of the power equipment; secondly, pay attention to the severity of the hazard consequences; finally, pay attention to the comprehensiveness of the hazard identification and the characteristics of each equipment.

Using the hazard checklist, you can clearly recognize the hazards of each device and the consequences caused by various factors, so that effective preventive measures can be taken.

(3) The main implementation steps of the hazard source checklist

(1)Investigation, organize the crew to conduct data investigation on each equipment;

(2)Data sorting, combined with the equipment "work register", to sort the data;

(3) Danger source identification, combined with the inspection system, effective identification of equipment hazard sources in accordance with the hazard source identification process;

(4) The secondary identification, combined with the inspection system, replaces the equipment to find the source of danger to reduce the error;

(5)Fill in the form and carefully fill in the "Hazard Source Inspection Form";

6) Summarize, summarize the "Hazard Source Checklist", and then classify and organize related hazards.

(4) Organization of daily inspections

(1)During the inspection process, the inspector must go deep into the cabin, understand the operation of the equipment installed in each cabin, and carefully observe the various indicators and parameters of the equipment.

(2)During the inspection, when a safety hazard is found, measures should be taken quickly, the relevant departments should be notified in time, and the cause should be analyzed afterwards.

(3) The personnel on duty should observe the various parameters of important equipment through the monitoring system, and find hidden safety hazards and abnormal changes in parameters to be checked and confirmed in the engine room.

(4)Fill in the hazard source inspection form, and the crew should check according to the hazard source inspection form, which can improve the quality of inspection and prevent the omission of some hazard sources.

\section{Example analysis of engine room fire hazard identification}

The power engine room is full of various power devices, machinery and electricity, and a large amount of combustible materials such as lubricating oil and heavy oil are stored. These 
are the hidden dangers of power system fire accidents. Since the time of the ship at sea far exceeds the time of berthing at the shore, once a fire occurs, it is more difficult to evacuate the crew and fight the fire, which will generally cause serious consequences such as casualties, ship damage and environmental pollution. In order to ensure the safety of crew and ship navigation, corresponding measures should be taken from the source to prevent engine room fires.

According to the fire characteristics of the engine room of the ship, and the two working conditions of the ship's navigation and berthing are analyzed, the improved LEC method is adopted to carry out the risk assessment of some hazards in the engine room.

Table 7. Risk assessment of engine room fire hazard (navigation state).

\begin{tabular}{|c|c|c|c|c|c|c|c|c|c|}
\hline $\begin{array}{c}\text { Hazard } \\
\text { source } \\
\text { code }\end{array}$ & $\begin{array}{c}\text { Object } \\
\text { number }\end{array}$ & Object name & $\begin{array}{c}\text { Hazard } \\
\text { source }\end{array}$ & L & E & C & D & $\begin{array}{c}\text { Risk } \\
\text { level }\end{array}$ & Remarks \\
\hline 1 & $16-06-01$ & $\begin{array}{c}\text { Lubricating } \\
\text { oil system }\end{array}$ & Oil spill & 10 & 10 & 7 & 700 & 1 & \\
\hline 2 & $\begin{array}{c}16-06- \\
02\end{array}$ & Fuel System & Oil spill & 10 & 10 & 40 & 4000 & 1 & \\
\hline 3 & $\begin{array}{c}16-06- \\
03\end{array}$ & $\begin{array}{c}\text { Electrical } \\
\text { System }\end{array}$ & Leakage & 3 & 10 & 40 & 1200 & 1 & \\
\hline
\end{tabular}

Table 8. Risk assessment table of engine room fire hazard (parking state).

\begin{tabular}{|c|c|c|c|c|c|c|c|c|c|}
\hline $\begin{array}{c}\text { Hazard } \\
\text { source } \\
\text { code }\end{array}$ & $\begin{array}{c}\text { Object } \\
\text { number }\end{array}$ & Object name & $\begin{array}{c}\text { Hazard } \\
\text { source }\end{array}$ & L & E & C & D & $\begin{array}{c}\text { Risk } \\
\text { level }\end{array}$ & Remarks \\
\hline 1 & $\begin{array}{c}16-06- \\
04\end{array}$ & $\begin{array}{c}\text { Lubricating } \\
\text { oil system }\end{array}$ & Oil spill & 6 & 6 & 7 & 252 & 1 & \\
\hline 2 & $\begin{array}{c}16-06- \\
05\end{array}$ & Fuel System & Oil spill & 10 & 6 & 7 & 420 & 1 & \\
\hline 3 & $\begin{array}{c}16-06- \\
06\end{array}$ & $\begin{array}{c}\text { Electrical } \\
\text { System }\end{array}$ & Leakage & 3 & 6 & 1 & 18 & 6 & \\
\hline
\end{tabular}

In the above risk assessment table, it is not difficult to find that the oil spill in the engine room is a first-class accident. After the oil spill occurs, if it is not handled in time or handled incorrectly, it will cause a major fire accident, especially when the ship is sailing. . According to the above table, it can be seen that the following factors affect the D value in the risk assessment:

1. The different states of the ship when it is sailing and when it is berthed will lead to different $\mathrm{D}$ values in the risk assessment;

2. Depending on the ship's status, the crew's duty time is different, and the severity of the consequences caused by the outbreak of the hazard source is different, which affects the value of D.

3. Depending on the ship's status, the severity of the consequences caused by the outbreak of the dangerous source is different, which affects the value of $D$.

4. Different failure modes affect the value of $\mathrm{D}$.

\section{Conclusion}

Ship power equipment, due to its working characteristics and working environment, has many factors affecting safety accidents. How to identify the hazard source simply and effectively is of great significance to the safe operation and management of the entire ship. According to the characteristics of the ship itself, this paper analyzes the characteristics of hazard sources of ship power equipment, gives the scope and classification method of hazard 
source identification, proposes hazard source identification methods and procedures, and gives specific organization and implementation methods. It is used to help the crew of the ship power department to quickly, effectively and scientifically identify the hazard sources in the engine room equipment. The method and process are simple and effective, easy to implement, and lay a foundation for the safety management of power equipment.

\section{References}

1. J. Pan, Q. Qi, D. Mao, Y. Ren, Y. Wang, Hazard source of rock burst and its hierarchical identification, Coal Mining, 2010, 15(02): 4-7+20.

2. Y. Zhou, H. Du, W. Zheng, Research on the Hazard Evaluation Method of External Manmade Events of Liquid Toxic Chemicals Around Nuclear Power Plants, Atomic Energy Science and Technology, 2015, 49(12): 2145-2149.

3. J. Song, W. Du, P. Guo, J. Zhang, R. Li, The current situation and predicament of the storage and quantity regulation of hazardous chemicals, Chemical Reagents, 2021, 43(03): 313-319.

4. Z. Chen, Safety analysis and evaluation of metal mine production system, Wuhan University of Science and Technology, 2009.

5. P. Zhao, Dangerous source concept differentiation and identification method, Civil Aviation of China, 2010(07): 52-53.

6. Y. Xu, W. Tang, S. Zhang, Research on identification method of hazard source of fire house explosion in ship engine room, Ship Science and Technology, 2010,32(6):24-30.

7. Y. Li, Y. Guo, M, Si, S Chen, Evaluation and control of hazards in high-rise building construction based on improved LEC evaluation method, Journal of China Three Gorges University (Natural Science Edition), 2019, 41(04): 55-59.

8. J. Zhao, The unique environmental adaptability of marine steam power plants, Ship Engineering, 2010, 32(05): 19-22.

9. Z. Cao, Ship fire and explosion risk analysis and related criteria research. Shanghai Jiaotong University, 2011.

10. M. Chen, Considerations on ship engine management and safe shipping in the new era, Internal Combustion Engines and Parts, 2020(07):206-207.

11. B. Liu, L. Tang, Research on Ship Safety Analysis Technology, Electronic Product Reliability and Environmental Testing, 2006(05):51-54.

12. Q. Zhang, F. Xie, On "Identification of Hazardous Factors", China Environmental Management, 2004, 000(002): 41-44.

13. Y. Xu, Research on risk-based ship fire and explosion hazard assessment method, Shanghai Jiaotong University, 2010.

14. Y. Luo, J. Pei, Risk analysis and safety evaluation, Beijing: Chemical Industry Press, 2016.

15. L. Huang, Research on the progress and risk management of the base station relocation project of Chengdu mobile line relocation, University of Electronic Science and Technology of China, 2011. 